\title{
Characteristics of the Calibration Curves of Copper for the Rapid Sorting of Steel Scrap by Means of Laser-induced Breakdown Spectroscopy under Ambient Air Atmospheres
}

\author{
Shunsuke KaShIWAKURA ${ }^{\dagger}$ and Kazuaki Wagatsuma \\ Institute for Materials Research, Tohoku University, 2-1-1 Katahira, Aoba, Sendai, Miyagi 980-8577, Japan
}

\begin{abstract}
For the rapid and precise sorting of steel scrap with relatively high contents of copper, laser-induced breakdown spectroscopy (LIBS) is a promising method. It has several advantages such that it can work under ambient air atmospheres, and specimens can be tested without any pretreatment, such as acid digestion, polishing of the surface of the specimens, etc. For the application of LIBS for actual steel scrap, we obtained emission spectra by an LIBS system, which was mainly comprised of an Nd:YAG laser, an Echelle-type spectrometer, and an ICCD detector. The standard reference materials (SRMs) of JISF FXS 350-352, which are Fe-Cu binary alloy and have certified concentrations of copper, were employed for making calibration lines. Considering spectral interferences from the emission lines of the iron matrix in the alloys, Cu I lines having wavelengths of 324.754 and $327.396 \mathrm{~nm}$ could be chosen. In five replicate measurements of each SRM, shorter delay times after laser irradiation and longer gate widths for detecting the transient emission signal are suggested to be the optimal experiment parameters. In the determination process, utilizing the calibration line from $\mathrm{Cu}$ I $327.396 \mathrm{~nm}$ was better because of less spectral interference. By using 200 pulsed laser shots for the measurement sequence, a limit of detection of $0.004 \mathrm{Cu}$ at\% could be obtained.
\end{abstract}

Keywords LIBS, steel scrap, tramp element, rapid sorting

(Received August 5, 2013; Accepted October 27, 2013; Published December 10, 2013)

\section{Introduction}

In recent years, the recycling of steel scrap has been energetically encouraged in order to comply with "Basic Act for the Promotion of the Recycling-Oriented Society", ${ }^{1}$ which has been enforced since 2000 in Japan. The amount of steel production in Japan has been around 100 million tons, and produced steels have been stocked and accumulated as infrastructures, cars, constructions, etc. ${ }^{2}$ Around one-third of the steel production in amount has been conducted by electric arc furnaces (EAF), which is the major recycle route for steel scrap. ${ }^{3}$

When recycling various types of steel scrap, clarifying and controlling their characters is of great concern. The classification of steel scrap has been conducted in Japan according to specifications by The Japan Ferrous Raw Materials Association. ${ }^{4}$ Especially, copper in steel products has been well recognized as one of the so-called tramp elements, ${ }^{5}$ which adversely affects hot processing. ${ }^{6}$ The threshold concentration of copper in steel products is usually $0.2 \mathrm{wt} \% .^{7}$ Since copper in steel products is difficult to be thermodynamically removed, and it thus tends to contaminate into steel scrap, ${ }^{8}$ it must be deeply concerned with the concentration of copper in recycled steel products, the so called "cyclic concentration".

In order to sort steel scrap according to the chemical compositions, we can apply laser-induced breakdown

† To whom correspondence should be addressed.

E-mail: shunsuke-k@imr.tohoku.ac.jp spectroscopy (LIBS) as an encouraging and promising analytical tool. -14 $^{9-1}$ can determine the chemical composition by remotesensing without any pretreatment of the targeted steel scrap. The diameter of the spot formed by the laser irradiation is usually less than $1 \mathrm{~mm}$; therefore, LIBS is classified as a non-destructive method. In LIBS, a pulsed laser beam that has a high power density is irradiated to the surface of a specimen. According to the laser irradiation, atoms located on the surface receive energy from the laser, and are then ablated from the surface. Some of the ablated atoms are excited/ionized, and then light emissions from a so-called "initial plasma" is generated. Released electrons in the initial plasma also receive energy from the laser, accelerate, and collide with the ablated atoms. The collision partner of the ablated atoms is also excited/ ionized, and then emits characteristic radiation during expansion of the plasma, a so-called "expanded plasma".

In determinating chemical composition by LIBS, the precision and repeatability of the calibration line is very important for reliable sorting of the pieces of steel scrap. In our previous work, it was revealed that the calibration line of copper in a laser-induced plasma (LIP) using low-pressure argon gas is enough to be employed for the elemental analysis of copper in Fe-based alloys. ${ }^{15}$ In that study, a criteria was made that a relative standard deviation (RSD) of below $10 \%$ is acceptable, and linear calibration curves of chromium in $\mathrm{Fe}-\mathrm{Cr}$ binary standard reference materials (SRMs) under a reduced argon atmosphere $\left(P_{\mathrm{Ar}}=2660 \mathrm{~Pa}\right)$ could be obtained in the concentration range of $5-20 \mathrm{Cr}$ at $\%$.

The background emission from LIP would worsen the 


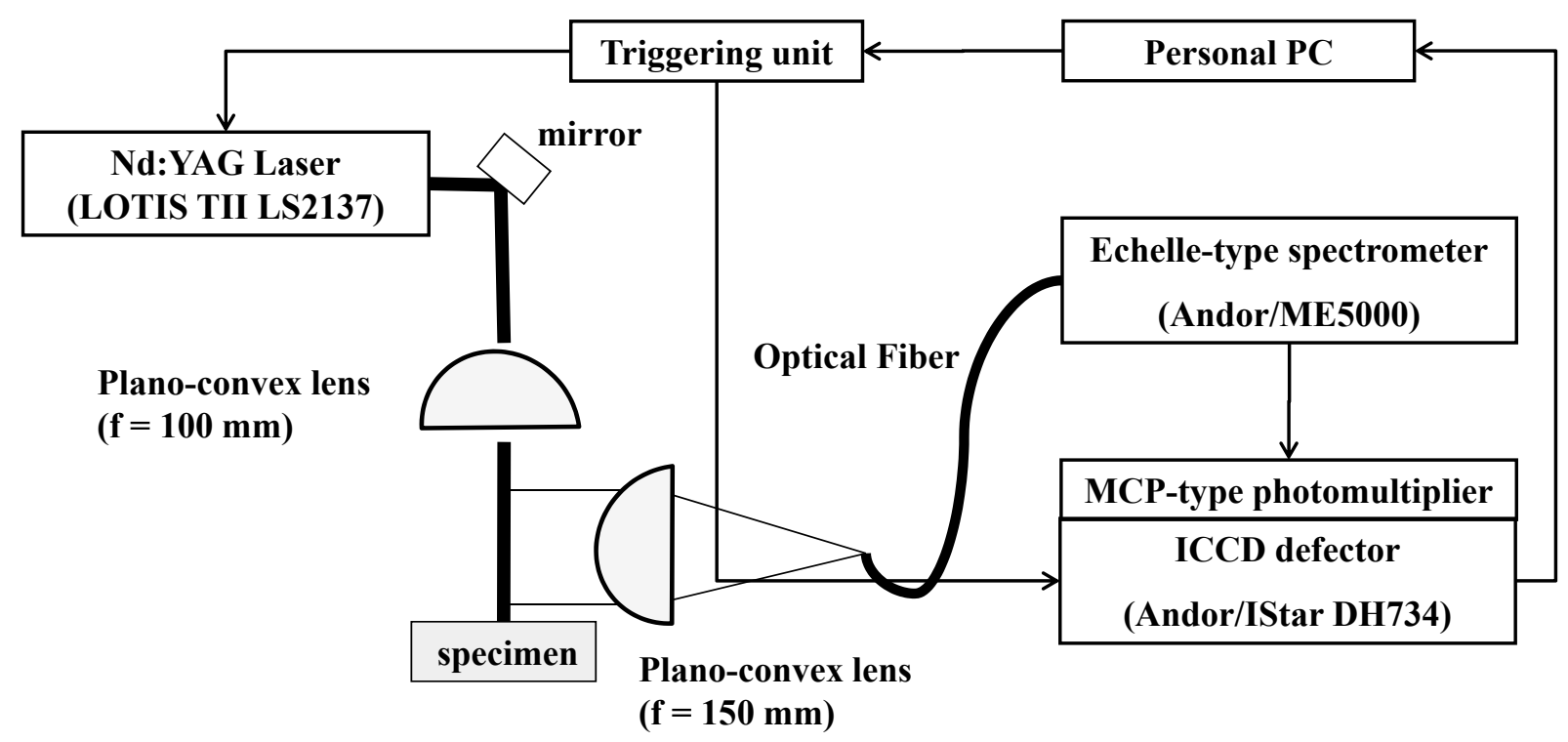

Fig. 1 Schematic diagram of the experimental apparatus.

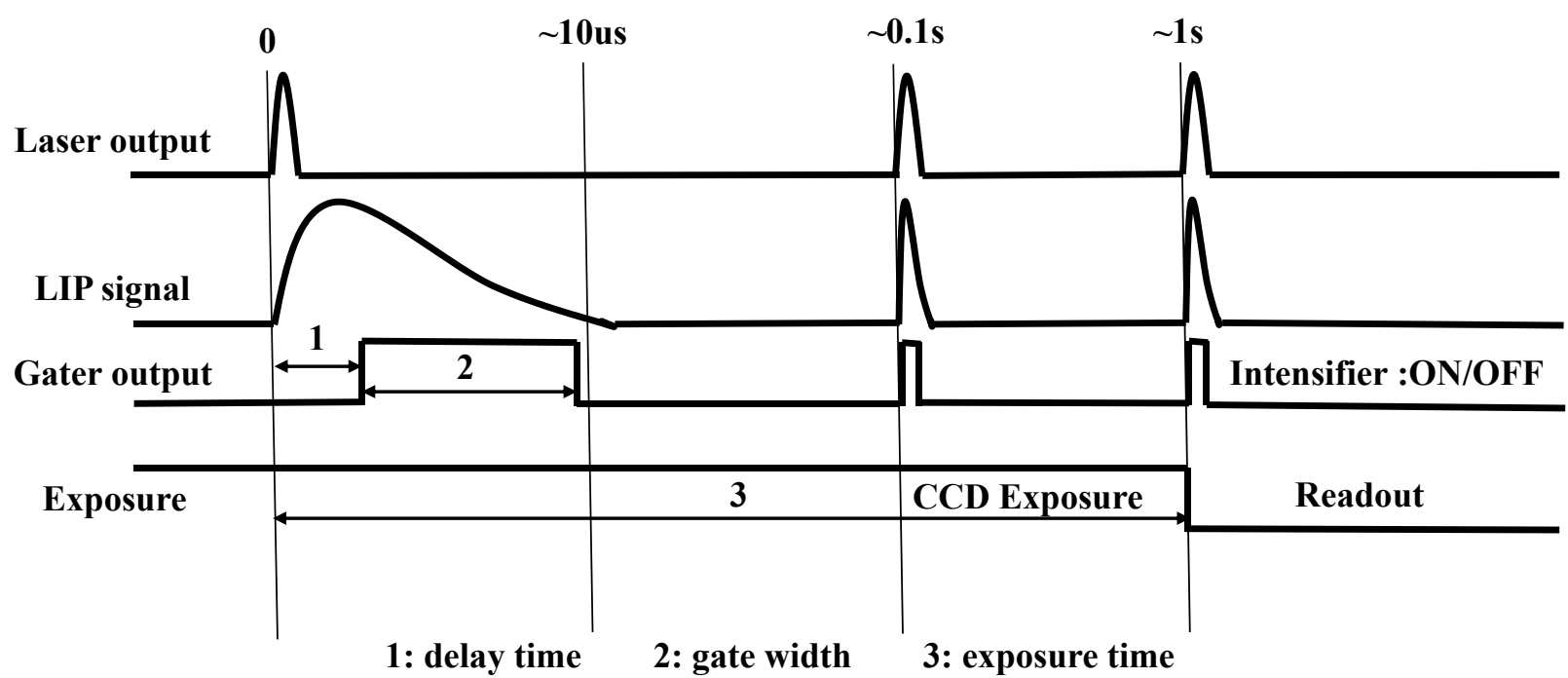

Fig. 2 Timing of the laser shots, LIP generation, intensifying, and detection.

precision of the calibration line due to: 1) recombination emission and 2) bremsstrahlung. Each effect can be described as follows:

$$
\begin{aligned}
& \text { 1) } \mathrm{G}^{+}+\mathrm{e}^{-}=\mathrm{G}+h v, \\
& \text { 2) } \mathrm{G}+\mathrm{e}^{-}(\text {fast })=\mathrm{G}+\mathrm{e}^{-}(\text {slow })+h v,
\end{aligned}
$$

where $h v$ means the continuum radiation of the background emission. In recombination emission, energetic electrons combine with gas ions for neutrization, and extra energy is emitted. In bremsstrahlung, energetic electrons are reaccelerated by gas atoms, and lose their kinetic energy, which results in the continuum radiation. In LIBS at atmospheric pressures, nitrogen molecules play an important role in these collision processes because the nitrogen molecule has many vibrational/rotational excited levels in different electronic states, and therefore it can become a major source for background spectra of LIBS. If these negative effects can be overcome, LIBS in air atmospheres can be a very powerful tool for the elemental analysis of varieties of steel scrap at a sorting site. Therefore, in this study we investigated precise calibration lines of copper for practical analysis by optimizing the experimental parameters in the open-air LIBS.

\section{Experimental}

The LIBS system utilized in this study comprised an Nd:YAG pulse laser (LS-2137, LOTIS TII), a three-dimensional sample stage, planoconvex lenses for collecting the laser and the emitted radiation, an optical fiber, an Echelle-type spectrometer (ME5000, Andor) and an ICCD detector (DH734-18F, Andor), as shown in Fig. 1. The wavelength, energy, duration, and frequency of the pulse laser were $532 \mathrm{~nm}$ (SHG mode), $80 \mathrm{~mJ} /$ pluse, $16-18 \mathrm{~ns}$, and $10 \mathrm{~Hz}$, respectively. A schematic 


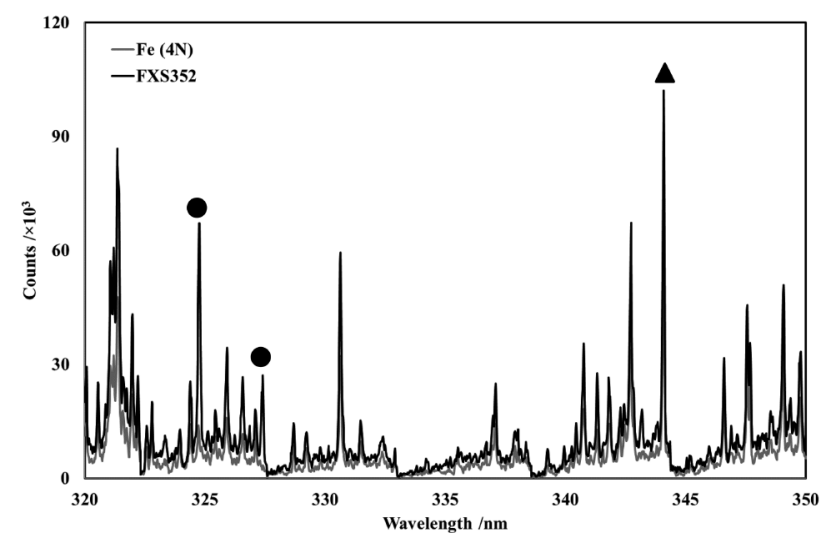

Fig. 3 Stacked LIP spectra of both FXS 352 and 4N-purity iron (delay time, $0.5 \mu \mathrm{s}$; gate width, $500 \mu \mathrm{s}$ ).

image of the timing of the laser irradiation, the formation of LIP, and detection is illustrated in Fig. 2. When a laser pulse having a width of $16-18 \mathrm{~ns}$ is irradiated onto the surface of specimens, the initial plasma was generated for $c a .0 .5 \mu \mathrm{s}$. And then the plasma was expanded upwards, and vanished. As a result of a preliminary experiment, we found that the emission signals from LIP in an air atmosphere was the most intensive at a time delay of $0.5 \mu \mathrm{s}$; therefore, we made a synchronization between the laser shot and the start of the emission detection by using a triggering unit, so that the values of the time delay could be varied from 0.5 to $10 \mu \mathrm{s}$. As another parameter for intensifying the emission signals, the gate width was adjusted from 0.5 to $500 \mu \mathrm{s}$, according to the delay time in order to obtain spectra with larger intensities and higher signal-tobackground ratios. The signals from the Echelle-type spectrometer were integrated on the ICCD; we set the exposure time of the ICCD for signal integration to $1.0 \mathrm{~s}$, as the maximum value in the Andor measuring system, enough to obtain all of the integrated emission signals when the laser irradiation was repeated at $10 \mathrm{~Hz}$. The amplification factor by a micro-channel plate photomultiplier in the ICCD detector, which could be varied from 0 to 250 , was also adjusted by an Andor Solis software interface in order to prevent saturation of the emission signals arriving at the micro-channel plate photomultiplier. Under this condition, the total measurement time was around $2 \mathrm{~s}$ for 10 laser shots irradiated in $1 \mathrm{~s}$, which was estimated at the interface.

For obtaining calibration lines, meaning the relationship between the time-integrated emission intensities and the contents of copper in the specimen, we adopted standard reference materials (SRMs) of FXS 350-352 certified by The Japan Iron and Steel Federation. The copper contents in FXS 350-352, were $0.2,0.5$, and $1.0 \mathrm{wt} \%$. Assuming that these SRMs could be regarded as being a $\mathrm{Fe}-\mathrm{Cu}$ binary alloy not containing any impurities, the copper concentration range could be converted to $0.18,0.44$, and 0.89 at $\%$, respectively. All of the measurements were conducted for five replicates in each specimen to evaluate the degree of fluctuation for calculating the RSDs.

\section{Result and Discussion}

Figure 3 shows the LIP emission spectra from the FXS 352 alloy and $4 \mathrm{~N}$-purity iron plate. Although all of the spectra were taken in the wavelength range of 200 to $950 \mathrm{~nm}$, the displayed
Table 1 A assignment of emission lines for making calibration lines

\begin{tabular}{ccccc}
\hline $\begin{array}{c}\text { Wavelength/ } \\
\text { nm }\end{array}$ & $\begin{array}{c}\text { Upper/ } \\
\mathrm{eV}\end{array}$ & \multicolumn{3}{c}{$\begin{array}{c}\text { Lowerer/ } \\
\mathrm{eV}\end{array}$} \\
\hline Cu I 324.754 & 3.8116 & $3 \mathrm{~d}^{10} 4 \mathrm{p}^{2}{ }^{2} \mathrm{P}_{3 / 2}$ & 0.0000 & $3 \mathrm{~d}^{10} 4 \mathrm{~s}^{2} \mathrm{~S}_{1 / 2}$ \\
Cu I 327.396 & 3.7858 & $3 \mathrm{~d}^{10} 4 \mathrm{p}^{2} \mathrm{P}_{1 / 2}$ & 0.0000 & $3 \mathrm{~d}^{10} 4 \mathrm{~s}^{2} \mathrm{~S}_{1 / 2}$ \\
Fe I 344.061 & 3.6025 & $3 \mathrm{~d}^{6} 4 \mathrm{~s} 4 \mathrm{p}^{5} \mathrm{P}_{3}$ & 0.0000 & $3 \mathrm{~d}^{6} 4 \mathrm{~s}^{2} \mathrm{D}_{4}$ \\
\hline
\end{tabular}

range was enlarged from 320 to $350 \mathrm{~nm}$. Since iron has a large number of atomic/ionic emission lines, emission lines of copper used for establishing calibration lines must be carefully selected so that the copper emission line has larger intensities without any spectral interferences with the iron emission lines. As a result, two lines of copper atomic emission, whose assignments are given in Table 1, could be selected. These copper lines marked with black circles are $\mathrm{Cu}$ I $324.754 \mathrm{~nm}$ and a $\mathrm{Cu}$ I $327.396 \mathrm{~nm}$, and also Fe I $344.061 \mathrm{~nm}$ was marked with a black triangle in Fig. 3. The characteristics of the Fe I $344.061 \mathrm{~nm}$ line is also listed in Table 1, because we utilized this line as an internal standard line, expecting that emission lines with similar upper levels would have similar emission characteristics. ${ }^{15}$ Since we utilized an Echelle-type spectrometer and ICCD detector, continuum background by recombination emission or bremsstrahlung could be observed as the jagged shape in Fig. 3 . The selection of resonance atomic lines is not generally suitable for making calibration lines due to a self-absorption effect: ${ }^{16-20}$ emission related to a resonance transition would be predominantly absorbed by the same kind of atom in the ground state, resulting in a decrease in the observed emission intensity. However, under the experimental conditions described above, we had no choice but to use the two resonance lines of copper because of relatively low concentrations of copper in $\mathrm{Fe}-\mathrm{Cu}$ SRMs as well as severe spectral interferences with a number of iron atomic/ionic emission lines; therefore, emission lines of iron that have a similar excited energy were considered to be favorable for the internal standard method.

In order to make calibration lines, peak areas of the $\mathrm{Cu} \mathrm{I}$ emission lines were calculated by subtracting the linearlyapproximated background and the sectional mensuration by trapezoidal rule. Since the transient response of the emission signals from LIP in air is generally unstable, due to differences of the laser energy in each shot, of the surface texture, of the convection, etc., it is important to optimize the measuring parameters for ICCD detection. Figure 4 shows the RSDs for the $\mathrm{Cu} \mathrm{I}$ emission lines for five-times measurements as a function of the gate widths. To obtain these plots, FXS 350 $(\mathrm{Cu}=0.18 \mathrm{at} \%)$ was employed and the delay time was fixed at 1 us. It was clearly observed that the RSDs decreased with an increase in the gate widths. Our previous report ${ }^{21}$ suggested that the expansion of the LIP would be suppressed by the air surrounding the plasma body, resulting in that the emission from the plasma could continue to be observed for more than $30 \mu \mathrm{s}$. The tendency shown in Fig. 4 implies that longer gate widths could average the fluctuation of the emission intensities by each laser shot. In Fig. 4, the RSDs estimated from the net peak areas and the peak area ratios are compared. The Fe I line was utilized as an internal standard to cancel out any difference in the emission intensity due to a difference in the ablation amounts from the specimens; however, the effect of the internal standard did not clearly appear. This phenomenon implies that the fluctuation of the net peak area of Fe I $344.061 \mathrm{~nm}$ are too high to cancel out those of the $\mathrm{Cu} \mathrm{I}$ lines. When we consider the 
sorting of various steel scrap, the concentrations of iron in them are not generally given. If the values of the peak-area ratios of the emission lines between copper and iron were adopted to make calibration lines, the discrepancy of the values between the SRMs and the pieces of scrap could be expected due to the difference of the iron concentrations in them; therefore, we utilized the net peak areas of the $\mathrm{Cu}$ I lines to make calibration lines, and the determination of copper in the pieces of scrap.

As described in the introduction, we should evaluate the background emission mainly by nitrogen molecules due to both the recombination emission and the bremsstrahlung. In Fig. 5, the spectra of FXS 350 with different delay times are stacked and displayed. As a background emission, a continuum is clearly observed in the wavelength range from $\mathrm{ca}$. 322.5 to $327.5 \mathrm{~nm}$, especially at a delay time of $0.5 \mu \mathrm{s}$. The continuum tends to decrease with an increase in the delay time, while the $\mathrm{Cu}$ I peaks are clearly observed in all of the spectra in Fig. 5.

Figure 6 describes calibration curves along with increasing the delay time. All of the calibration lines bend downwards at higher copper contents in the FXS standards, which typically suggested the occurrence of self-absorption. While the peak area of $\mathrm{Cu}$ I $327.396 \mathrm{~nm}$ was almost zero in a $4 \mathrm{~N}$-purity iron sample, that of $\mathrm{Cu}$ I $324.754 \mathrm{~nm}$ was non-zero, which would derive from a slight interference by the emission line of the $\mathrm{Fe} I$

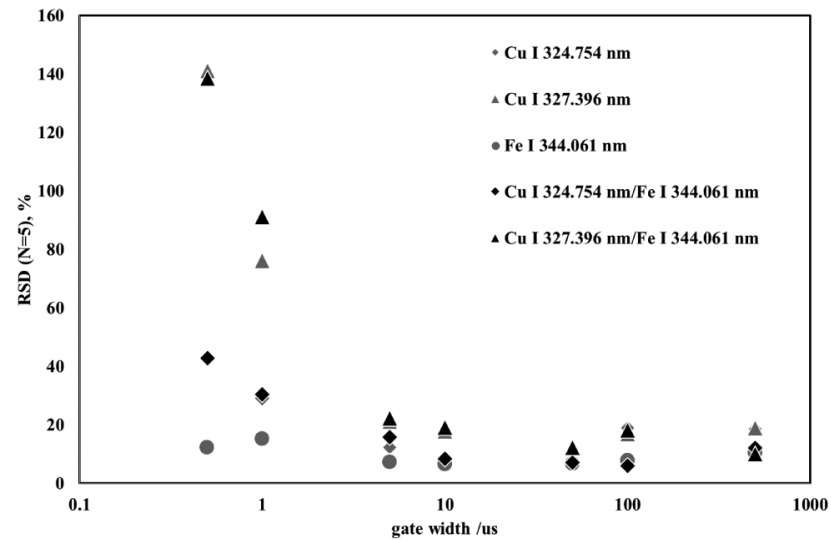

Fig. 4 Relationship between the RSDs from the peak areas or the peak area ratios and the gate widths at a delay time of $1 \mu \mathrm{s}$.
$324.742 \mathrm{~nm}$ line. We have also obtained linear calibration curves of copper in the same FXS standards under an evacuated atmosphere using argon gas, ${ }^{22}$ and such a difference of the calibration curves can be explained by the degree of self-absorption. That is, the expansion and decay of the LIP in a low-pressure atmosphere tends to proceed more easily, ${ }^{23}$ whereas it is blocked in an ambient atmosphere by surrounding air gases. That results in a difference in the number density of ablated atoms in the ground level, and affects the probability of occurrence of self-absorption. In Fig. 6, the peak areas obtained in FXS $352(\mathrm{Cu}=0.89$ at $\%)$ tend to be smaller than those of FXS $351(\mathrm{Cu}=0.44$ at\%) with an increase in the delay time, representing the progress of self-absorption. This can be reasonable because when the delay time is prolonged, the number of copper atoms in excited levels is reduced, while that in the ground level increases. Although the background emission became elevated in the early stage of emission, we adopted $0.5 \mu \mathrm{s}$ of the delay time because the degree of selfabsorption effect was less than that for longer delay times.

The elemental for actual pieces of steel scrap primarily requires a rapid detection of copper contents; for this purpose, an LIBS measurement with fewer laser shots is recommended. In other words, the detection of $0.2 \mathrm{wt} \%$ of copper would be required by this LIBS measurement. As the next step, an improvement in the accuracy of the measurement could be

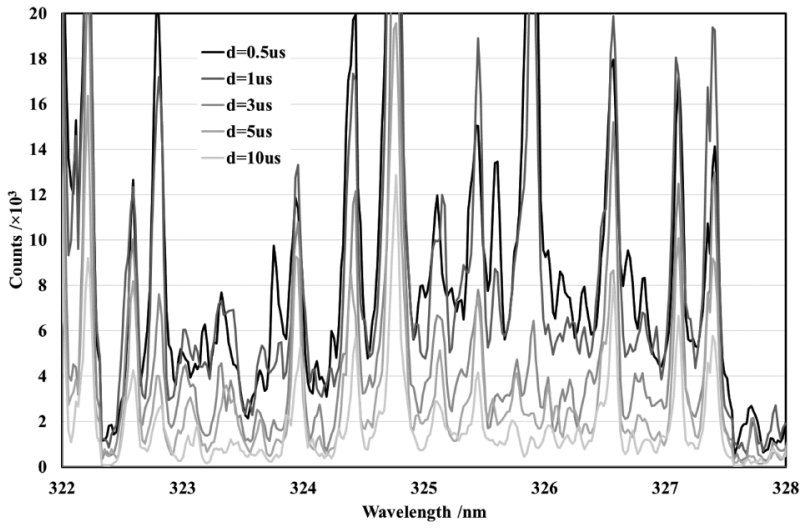

Fig. 5 Stacked LIP spectra from FXS 350 along with the delay time.
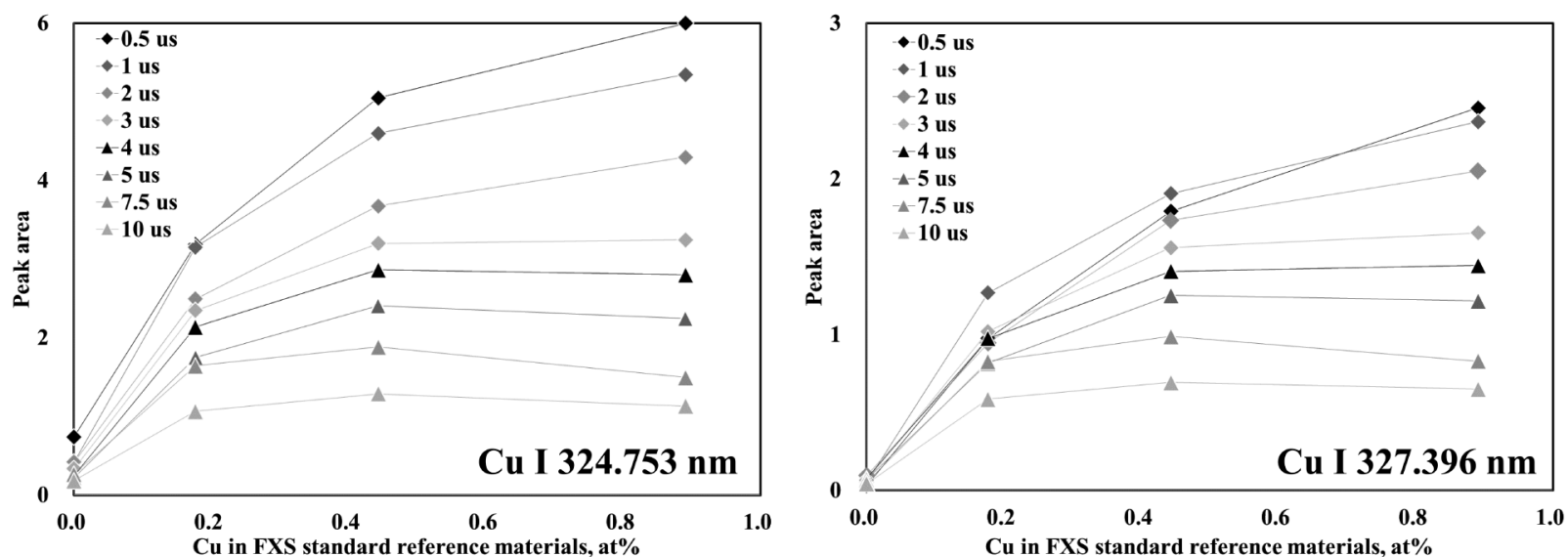

Fig. 6 Calibration curves of copper by FXS SRMs by changing the delay times, when the gate width was fixed at $500 \mu \mathrm{s}$ 

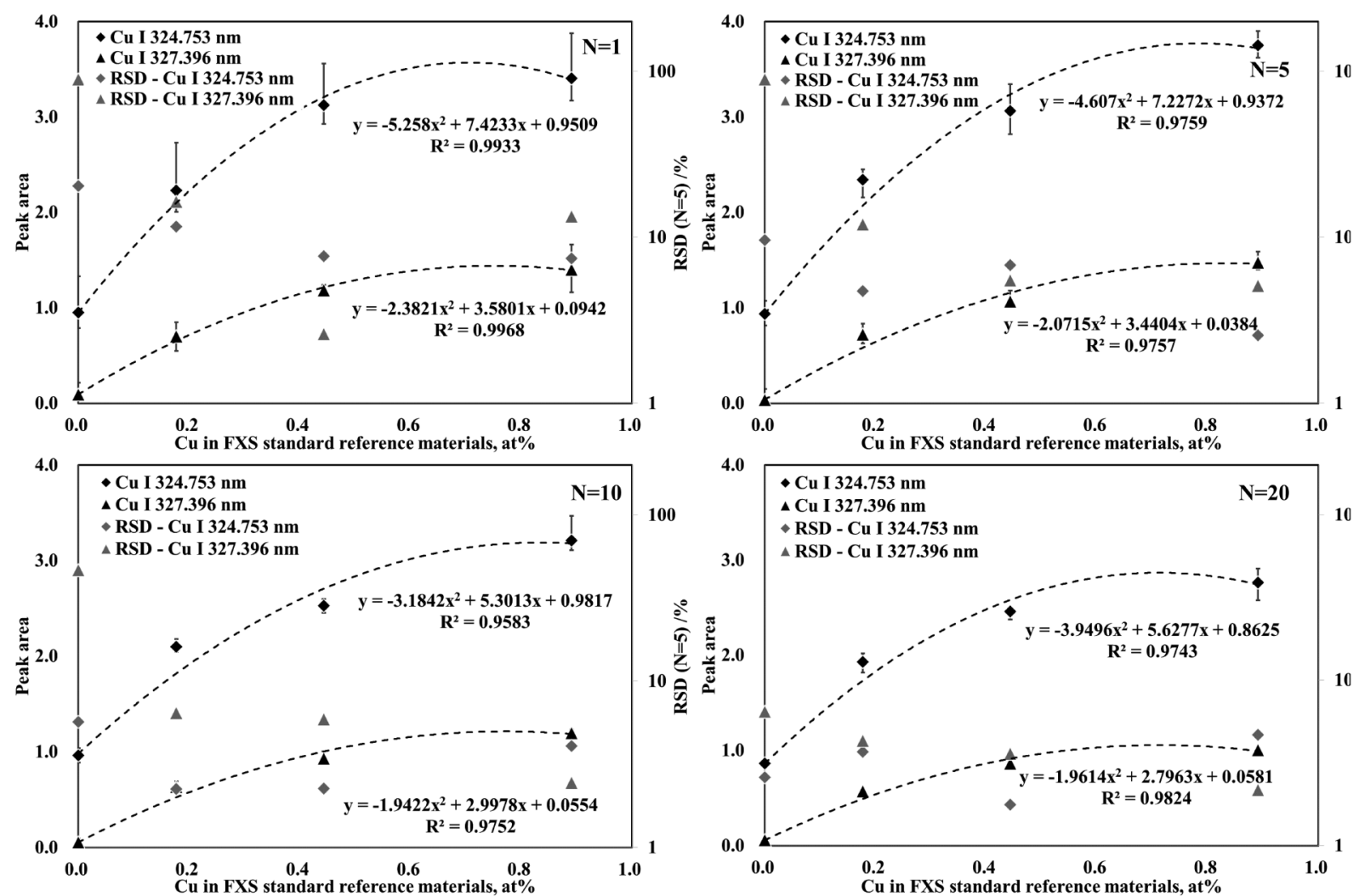

Fig. 7 Calibration curves of copper by FXS SRMs by changing the laser shots, when the delay time and gate width were fixed at 0.5 and $500 \mu$ s, respectively.

Table 2 RSDs and limits of detection from the calibration lines listed in Fig. 6

\begin{tabular}{cccccccc}
\hline $\begin{array}{c}\text { Wavelength/ } \\
\text { nm }\end{array}$ & $\begin{array}{c}\text { Laser shots/ } \\
\text { times }\end{array}$ & $\begin{array}{c}\text { RSD, } \\
\%\end{array}$ & Fe & 350 & 351 & 352 & $\begin{array}{c}\text { Limits of } \\
\text { detection, } \\
\text { at } \%\end{array}$ \\
\hline Cu I 324.753 & 10 & & 20.3 & 11.6 & 7.7 & 7.5 & 0.094 \\
& 50 & & 9.6 & 4.8 & 6.8 & 2.6 & 0.043 \\
& 100 & & 5.6 & 2.2 & 2.6 & 4.1 & 0.035 \\
& 200 & & 2.3 & 3.7 & 1.8 & 4.7 & 0.012 \\
$\mathrm{Cu}$ I 327.396 & 10 & & 89.7 & 16.4 & 2.6 & 13.3 & 0.084 \\
& 50 & & 89.7 & 11.9 & 5.5 & 5.1 & 0.034 \\
& 100 & & 46.7 & 6.5 & 5.9 & 2.5 & 0.030 \\
& 200 & & 6.4 & 4.3 & 3.6 & 2.2 & 0.004 \\
\hline
\end{tabular}

conducted by accumulating emission signals with the change in the laser shots from 10 to 200 . The total measurement times varied from 2.1 to $42.6 \mathrm{~s}$. The result is shown in Fig. 7, and it is obvious that the fluctuation of the measured peak area ratio drastically decreased with an increase in the repetition times. From the quadratic regression functions listed in Fig. 7, the limits of detection by the Kaiser 3-sigma criterion are listed in Table 2. In order to calculate the limit of detection, the intercepts of the quadratic functions were equally set to the average values of the peak area ratios in the $4 \mathrm{~N}$-purity iron. It was revealed that the RSDs as well as the limit of detections could be greatly improved by increasing the repetition times. It should be noted that the limits of detection from $\mathrm{Cu}$ I 327.396 $\mathrm{nm}$ are better than those of $\mathrm{Cu} I 324.753 \mathrm{~nm}$, because the peak area of $\mathrm{Cu}$ I $324.753 \mathrm{~nm}$ includes the peak area of Fe I 324.742 $\mathrm{nm}$ as the spectral interference.

As a final step, LIBS under the ambient air condition was applied to measurements of the copper contents of three pieces of steel scrap named as scrap $1-3$, which were obtained from a market for recycling. The copper contents in these pieces of steel scrap were measured by means of handheld-type X-ray fluorescence analysis (DP2000, Olympus). They were determined by a fundamental parameter method with two beams: $40 \mathrm{~s}$ of irradiation of a $40 \mathrm{kV}$ beam and $20 \mathrm{~s}$ of irradiation of a $8 \mathrm{kV}$ beam. The limit of detection of copper in a Fe-based alloy in this XRF is ensured below $10 \mathrm{ppmw}$, and the determined concentration of copper in the pieces of scrap are $0.031 \mathrm{wt} \%$ for scrap 1, and non-detected for scrap 2 and 3 . The scrap 1 mainly consists of iron and zinc, and theie compositions are 58.3 and $37.3 \mathrm{wt} \%$, respectively.

The results of LIBS measurements are given in Table 3 . It was conducted under the same conditions as described in Table 2. We could not detect the copper contents in scrap 2 and 3 , which are consistent with the results by XRF measurements. The detection of copper contents in scrap 1 by the LIBS measurement was successful only in the 200-laser-shot condition due to the sufficient limit of detection. The determined values of copper contents in scrap 1 could be converted to 0.024 and $0.039 \mathrm{wt} \%$, respectively, with the assumption that scrap 1 is Fe-Zn-Cu ternary alloy. Compared to the XRF analysis, it seems that the determination of copper contents in scrap 1 was successful; however, we could not the detailed accuracy of this determination due to a lack of variations of scrap specimens. Further investigation for targets of steels scrap with higher copper contents (e.g. more than $0.1 \mathrm{wt} \%$ ) is needed for our future study. 
Table 3 Determination of $\mathrm{Cu}$ contents in 3 types of steel scrap using the calibration lines listed in Table 2

\begin{tabular}{|c|c|c|c|c|c|}
\hline $\begin{array}{l}\text { Wavelength/ } \\
\mathrm{nm}\end{array}$ & $\begin{array}{l}\text { Laser shots/ } \\
\text { times }\end{array}$ & $\begin{array}{c}\text { Limits of } \\
\text { Detection, at } \%\end{array}$ & $\begin{array}{c}\mathrm{Cu} \text { in } \\
\text { Scrap 1, at\% }\end{array}$ & $\begin{array}{c}\mathrm{Cu} \text { in } \\
\text { Scrap 2, at } \%\end{array}$ & $\begin{array}{c}\mathrm{Cu} \text { in } \\
\text { Scrap 3, at } \%\end{array}$ \\
\hline \multirow[t]{4}{*}{$\mathrm{Cu}$ I 324.753} & 10 & 0.094 & Not detected & Not detected & Not detected \\
\hline & 50 & 0.043 & Not detected & Not detected & Not detected \\
\hline & 100 & 0.035 & Not detected & Not detected & Not detected \\
\hline & 200 & 0.012 & 0.022 & Not detected & Not detected \\
\hline \multirow[t]{4}{*}{ Cu I 327.396} & 10 & 0.084 & Not detected & Not detected & Not detected \\
\hline & 50 & 0.034 & Not detected & Not detected & Not detected \\
\hline & 100 & 0.030 & Not detected & Not detected & Not detected \\
\hline & 200 & 0.004 & 0.037 & Not detected & Not detected \\
\hline
\end{tabular}

\section{Conclusions}

The aim of this study was to optimize the experimental parameters for obtaining calibration curves of copper in $\mathrm{Fe}-\mathrm{Cu}$ binary SRMs by laser-induced breakdown spectroscopy. The emission lines of $\mathrm{Cu}$ I $324.754 \mathrm{~nm}$ and $\mathrm{Cu}$ I $327.396 \mathrm{~nm}$ were found to be candidates for the detection of copper in the $\mathrm{Fe}-\mathrm{Cu}$ alloy, though they were resonance lines that would suffer from self-absorption. Since prolonged gate widths are sufficient to detect the transient emission, and the decay of the LIP was effective for the reduction of fluctuation of the emission signals, the gate width was set to $500 \mu \mathrm{s}$ as an optimal parameter, because it could average the emission from the LIP by each laser shot. A shorter delay time was also favorable in order to suppress the self-absorption effect. The accuracy of the calibration curves could be improved by repeating the measurement sequence. A limit of detection of $0.004 \mathrm{Cu}$ at $\%$ could be achieved by 200 laser shots, and these optimized experimental conditions might be applied for actual pieces of steel scrap.

\section{Acknowledgements}

This research is supported by a Grand-in-Aid from the Ministry of Education, Science, Sports and Culture of Japan (No. 23310049). Several parts of the setups were installed under support of the A-STEP program in Japan Science and Technology Agency (No. 241FT0286) and ISIJ Research Promotion Grant (Incl. Ishihara/Asada Grant) by the Iron and Steel Institute of Japan.

\section{References}

1. The Basic Law for Establishing the Recycling-based Society, The Ministry of Environment, Japan, 2000, http:// law.e-gov.go.jp/htmldata/H12/H12HO110.html.

2. The Japan Iron and Steel Federation, http://www.jisf.or.jp/ data/.

3. Non-Intergrated Steel Producers Association, http://www. fudenkou.jp/about_03.html.
4. Uniform Standards of Ferrous Scrap, The Japan Ferrous Raw Materials Association, http://www.tetsugen.gol.com/ kikaku/index.htm.

5. The Society of Materials Science, Japan, http://www.jsms. jp/word/index-kato.html.

6. L. Savov, E. Volkova, and D. Janke, RMZ - Mater Geoenviron., 2003, 50, 627.

7. T. Kajitani, M. Wakoh, N. Tokumitsu, S. Ogibayashi, and S. Mizoguchi, Tetsu-to-Hagane (in Japanese), 1995, 81, 185 .

8. K. Yamamoto, T. Toh, H. Hamatani, K. Tsunenari, K. Umetsu, Y. Maruki, S. Takeuchi, and Y. Yamada, Engineering Report of Nippon Steel \& Sumitomo Metal (in Japanese), 2012, 394, 69.

9. T. M. Naeem, H. Matsuta, and K. Wagatsuma, ISIJ Int., 2002, 42, 1318.

10. K. Kuzuya, M. Murakami, and N. Maruyama, Spectrochim. Acta, Part B, 2003, 58, 957.

11. Y. Ushirozawa and K. Wagatsuma, Anal. Sci., 2006, 22, 1011.

12. Y. Iida, Spectrochim. Acta, Part B, 1990, 45, 1353.

13. T. L. Thiem, R. H. Salter, J.A. Gardner, Y. I. Lee, and J. Sneddon, Appl. Scpectrosc., 1994, 48, 4.

14. L. Fornarini, F. Colao, and R. Fantoni, Spectrochim. Acta, Part B, 2005, 60, 1186 .

15. H. Shimada and K. Wagatsuma, Bunseki Kagaku, 2011, 60 , 59 .

16. V. Lazic, F. Brrbini, and R. Fantoni, Spectrochim. Acta, Part B, 2001, 56, 807.

17. G. Gupta, B. Suri, and A. Verma, J. Alloys Compd., 2011, 509, 3740.

18. M. Garcimuno, M. Pace, and G. Bertuccelli, Opt. Laser Technol., 2013, 47, 26.

19. A. Sarkar, D. Alamelu, and S. Aggarwal, Opt. Laser Technol., 2013, 47, 30.

20. S. Beatrice, A. David, and A. Sylvestre, Spectrochim. Acta, Part B, 2005, 60, 479.

21. S. Kashiwakura and K. Wagatsuma, CAMP-ISIJ, 2012, 25, 1264.

22. L. Zhang and K. Wagastuma, ISIJ Int., 2013, 58, in press.

23. L. Zhang, S. Kashiwakura, and K. Wagatsuma, Key Eng. Mater., 2012, 508, 331. 